NBER WORKING PAPER SERIES

\title{
A THEORY OF GRADUAL TRADE LIBERALIZATION
}

Robert W. Staiger

Working Paper No. 4620

\section{NATIONAL BUREAU OF ECONOMIC RESEARCH 1050 Massachusetts Avenue \\ Cambridge, MA 02138}

January, 1994

\begin{abstract}
An earlier version of this paper was presented at the Conference on New Directions in Trade Theory, Ann Arbor, October 29-30, 1993. I thank Kyle Bagwell, Robert Baldwin, John Kennan, Guido Tabellini and seminar participants at The University of Wisconsin for helpful discussions. and Max Corden, Marie Thursby, and conference participants for very helpful comments. This paper is part of NBER's research program in Intemational Trade and Investment. Any opinions expressed are those of the author and not those of the National Bureau of Economic Research.
\end{abstract}




\title{
A THEORY OF GRADUAL TRADE LIBERALIZATION
}

\begin{abstract}
This paper proposes a theory of gradual trade liberalization. I consider countries that are limited to self-enforcing arrangements in their trade relations. I argue that enforcement problems associated with the maintenance of low cooperative tariffs are exacerbated by the presence of resources in the import-competing sector that are (or potentially could be) eaming rents from their sector-specific skills. Intuitively, by being able to transform into rents a portion of what otherwise would be dead weight loss under a tariff hike, the presence of such resources makes deviation from a low cooperative tariff to a high tariff more desirable for the deviating country, and makes punishments under reciprocally high tariffs less painful. Hence, the presence of rentcollecting resources in an import-competing sector acts as a deterrent to trade liberalization. But if an initial "round" of liberalization can induce at least a portion of these resources in the import-competing sector to relocate to the rest of the economy, and if by not using their sectorspecific skills these resources stand to lose them, then the enforcement issues associated with their presence will also diminish over time, and further rounds of liberalization are made possible by the effects of the initial round. I formalize this gradual process of trade liberalization, and explore the consequences of a failed round of liberalization for the ability to maintain current levels of cooperation.
\end{abstract}

Robert W. Staiger Department of Economics The University of Wisconsin 1180 Observatory Drive Madison, WI 53706 and NBER 


\section{Introduction}

There are many questions that arise in the theory of trade policy which presuppose the view that trade liberalization is a gradual, dynamic process. An example of great current interest is the question of whether the proliferation of regional trade agreements might slow down or speed up the process of multilateral trade liberalization under the General Agreement on Tariffs and Trade (GATT), but other examples abound. Trade adjustment assistance is often defended on the grounds that it helps to facilitate the process of trade liberalization. Political lobbies and labor unions representing import-competing interests are seen as retarding the process of trade liberalization, while GATTs most-favored-nation principle is perceived as spurring it on.

There are even important questions about the dynamics of the liberalization process itself. The GATT process of on-going repeated "rounds" of liberalization has been credited with generating the momentum for the successful multilateral tariff-cutting experience of the post-war period, and has lead to an informal "bicycle" theory of GATT: unless you keep pedalling, you will fall off (Bhagwati, 1988, p. 41). The bicycle view of GATT also underlies the concern shared by many regarding the likely consequences of a failure to bring the (finally completed) Uruguay Round of GATT negotiations to a successful conclusion (see for example, Economic Report of The President, 1992, p. 193). This concern amounts to the view that a failure to conclude the Uruguay Round would not simply have meant a continuation of the status quo, but rather a retreat from existing levels of international cooperation in trade policy. 
While the perception of trade liberalization as a gradual process is pervasive, and while answers to many of the central questions in the theory of trade policy require that the process be thought of in this way, we have no satisfactory theory that would yield a gradual process of trade liberalization as an endogenous outcome. The purpose of this paper is to provide a theory of trade liberalization in which the process of liberalization is inherently time-consuming. In the model I present below, partial liberalization today builds the foundation for the possibility of further liberalization at some point in the future.

My starting point is the presumption that, among countries that are attempting reciprocally to lower trade barriers, the inability to commit to policies that are jointly optimal but individually suboptimal is a key ingredient which gives rise ultimately to a gradual trade liberalization process. The idea that government commitment problems can lead to gradualism in the reform process is not new. Dewatripont and Roland (1992) argue that a government's inability to commit to its domestic agents not to use information revealed in a partial reform for the design of later reforms can lead to gradualism in the optimal reform path. Matsuyama (1990) shows that if a government lacks commitment to an announced liberalization schedule in a game of timing between it and a domestic industry over when to invest (the industry) and when to liberalize (the government), then equilibrium liberalization may be delayed. However, neither paper focuses on the commitment problems that arise internationally across governments, a focus which I adopt here and which seems particularly' appropriate when considering gradualism in multilateral trade liberalization.

In focussing on the commitment problems across countries associated with international cooperation in trade policy, 1 am building on the work of Jensen and Thursby 
(1984), Dixit (1987), Bagwell and Staiger (1990, 1993a, 1993b), and others. This work adopts the view that enforcement issues are central to the dynamic behavior of trade policy in a world where countries attempt to maintain cooperative trade policies and that, in practice, the enforcement of agreed-upon behavior under GATT is limited by the severity of retaliation that can be credibly threatened against an offender by its trading partners. I therefore model intemational cooperation in trade policy as necessarily self-enforcing, in that it involves balancing the current gains from deviating unilaterally from an agreed-upon trade policy against the future losses from forfeiting the benefits of multilateral cooperation that such a unilateral defection would imply. What differentiates this paper from those before it and what, when combined with issues of international policy commitment, leads to a model of gradual trade liberalization, is that (i) I allow resources to change sectors in response to changing tariff levels, and (ii) I consider the possibility that the sector-specific skills of import-competing workers displaced by tariff reductions may depreciate over time.'

\footnotetext{
1 In an unpublished paper that was brought to my attention after presentation of the first draft of this paper at the Michigan conference, Devereux (1992) explores the two-way interaction between trade liberalization and economic growth in a setting in which production technologies are characterized by learning-by-doing and governments set tariffs in a repeated game. Although Devereux's focus is on the relationship between economic growth and trade liberalization, trade liberalization is characterized by a gradual process in his model. However, gradualism does not emerge as an inherent part of the liberalization process itself, but rather derives from the gradual process of learning by doing that is central to his model. That is, in Devereux's model, while the maximal rate of trade liberalization is gradual, it is independent of the actual rate of liberalization, depending fundamentally only on the dynamics of the underlying leaming-by-doing process in production: There is thus no link between the depth of trade liberalization undertaken today and liberalization possibilities in the future. In the model I develop here, the degree of current liberalization conditions future liberalization possibilities at each point in time, so that liberalization is an inherently dynamic and gradual process. I thank Scott Taylor for bringing Devereux's paper to my attention.
} 
Within this setting, I explore how the government's incentive problem associated with maintaining low cooperative tariffs is exacerbated by the presence of resources in the importcompeting sector that are (or could potentially be) earning rents from their sector-specific skills. Intuitively, by being able to capture the rents created by the government under a tariff hike, the presence of such resources enhances the government's temptation to deviate from a low cooperative tariff to a high tariff while it also reduces the pain of the reciprocally-high tariff punishment that would follow such a deviation. Hence, the presence of rent-collecting resources in an import-competing sector acts as a deterrent to trade liberalization. But this suggests in turn that some initial progress in trade liberalization, which is sufficient to lead to the relocation of a portion of the existing import-competing workers out of the importcompeting sector, might eventually pave the way for greater trade liberalization in the future, as the workers who leave the import-competing sector eventually lose their industry-specific import-competing skills -- and hence their ability to earn rents in the import-competing sector were the government to retum to a higher tariff. It is this dynamic complementarity which I attempt to formalize in what follows.

The rest of the paper proceeds as follows. In Section II, I formalize the basic incentive problem for trade liberalization that is created by the presence of rent-earning import-competing workers in a stationary environment in which workers keep their importcompeting skills even if they are not currently working in the import-competing sector. Section III then introduces the assumption that import-competing workers who leave the sector face the possibility of losing their sector-specific skills, and characterizes the nonstationary, gradual, process of trade liberalization that results. In Section IV, I apply the 
model to explore the notion that the failure of a round to achieve further liberalization may lead to a retreat from existing levels of tariff cooperation. Section V concludes.

\section{A Stationary Model of Trade Liberalization}

I consider two symmetric countries, a home (no*) country and a foreign(*) country. Each country chooses import tariffs for its import-competing industry, while its export industry must operate under the import tariffs chosen by its trading partner. Countries share identical linear demands $(\alpha-\beta \mathrm{P})$ for the product of each industry. Production technologies in these two industries are linear, using labor as the sole input: in each industry and in each country, one unit of output can be produced by one unit of effective labor input. With $\tau$ and $\tau^{\circ}$ denoting the (specific) impediments to trade into the import-competing industry of the home and foreign country, respectively, with $w_{m}, w_{x}, w_{m}^{*}$, and $w_{x}^{*}$ denoting the local wage per unit of effective labor in the import-competing and export sector of the home and foreign country, respectively, and with $P_{m}, P_{x}, P_{m}^{*}$, and $P_{x}^{*}$ denoting the local price of the import-competing and export good in the home and foreign country, respectively, I have

$$
\begin{aligned}
& w_{m}=P_{m} ; w_{x}=P_{x} ; w_{m}^{\cdot}=P_{m}^{*} ; w_{x}^{\cdot}=P_{x}^{*} \\
& P_{m}=P_{x}^{\cdot}+\tau ; P_{m}^{\cdot}=P_{x}+\tau^{*}
\end{aligned}
$$

provided that $\tau$ and $\tau^{\bullet}$ are non-prohibitive. Finally, in addition to its export and importcompeting industries, each country has a large rest-of-economy sector. 
There are three types of labor in these economies. First, there are workers that are particularly well-suited to work in the import-competing sector of their economy. Each of these workers is endowed with 1 efficiency unit of labor which is equally productive in the import-competing sector or in the rest-of-economy sector, but each such worker is also endowed with $\gamma$ efficiency units of labor reflecting sector specific skills, i.e., worth nothing outside the import-competing sector. I assume that there are $e /(1+\gamma)$ such workers in each cconomy (and thus that their effective supply when employed in the import-competing sector is e), and refer to them as "import-competing" workers. In addition, each economy has a large supply of workers endowed with no sector-specific skills, which I refer to as "rest-ofeconomy" workers, who are endowed with 1 efficiency unit of non-sector-specific labor, and whose supply into the import-competing sector is infinitely elastic at the fixed rest-ofeconomy market wage $\bar{w}$. Finally, production in the export sector of each economy also requires special skills. I assume that each economy is endowed with $\mathrm{E}$ effective workers with such skills, and that there is no possibility of intersectoral labor movement in or out of this sector.

These assumptions allow me to focus on resource movements into and out of the import-competing sector, and in particular on the issues raised when such resource movements are an integral part of the process of trade liberalization. I ignore for now the analogous resource movements that would arise into and out of the export sector, and comment on their importance in the conclusion.

Each country's effective labor supply curve into its import-competing sector--and hence its supply curve for the import-competing good--will look as depicted by the dashed 
line in Figure 1 labeled S. The e effective import-competing workers will choose to locate in the import-competing sector at an import price of $\bar{w} /(1+\gamma)$ or greater, and would choose to locate in the rest-of-economy sector otherwise. Rest-of-economy workers would choose to enter the import-competing sector at an import price of $\vec{w}$ or greater. Figure 1 also depicts the linear product demand curve for the import-competing good by the dashed line labeled D. drawn for the case in which the price of the import-competing good would rise to $\bar{w}$ in the absence of trade. The difference between these two is the country's import demand, and is represented in Figure 1 as the solid line labeled M.

I will be interested in the case where, facing free trade, a portion of a country's import-competing workers would choose to locate in the rest-of-economy sector. In fact, though inessential, it will prove convenient to assume that free trade would be just sufficient to induce all import-competing workers to locate in the rest-of-economy sector. This amounts to the assumption that each country's export sector is endowed with enough labor to satisfy the demand from both countries at a world price of $\bar{w} /(1+\gamma)$, or

$$
E=2\left(\alpha-\beta \frac{\bar{w}}{1+\gamma}\right)
$$

Figure 1 depicts the export supply curve under (3) by the solid line labeled X. The other cases, in which (3) is violated with an inequality in either direction, are analytically messier but not qualitatively different.

It is now straightforward to establish that equilibrium domestic prices as functions of $\tau$ and $\tau^{*}$ are given by 


$$
\begin{aligned}
& \bar{w} \quad \text { for } e / \beta+\frac{2 \gamma}{1+\gamma} \bar{w} \leq \tau \leq \bar{\tau} \\
& P_{m}(\tau)=1 \frac{\bar{w}}{(1+\gamma)}+\frac{\tau-e / \beta}{2} \quad \text { for } e / \beta \leq \tau \leq e / \beta+\frac{2 \gamma}{1+\gamma} \bar{w} \\
& \frac{\bar{w}}{(1+\gamma)} \quad \text { for } 0 \leq \tau \leq e / \beta \\
& \bar{w}-\tau^{*} \quad \text { for } e / \beta+\frac{2 \gamma}{1+\gamma} \bar{w} \leq \tau^{*} \leq \bar{\tau} \\
& P_{x}\left(\tau^{*}\right)=\left\{\frac{\bar{w}}{1+\gamma}-\frac{\tau^{*}+e / \beta}{2} \quad \text { for } e / \beta \leq \tau^{*} \leq e / \beta+\frac{2 \gamma}{1+\gamma} \bar{w}\right. \\
& \frac{\bar{w}}{(1+\gamma)}-\tau^{*} \quad \text { for } 0 \leq \tau^{*} \leq e / \beta
\end{aligned}
$$

where $\bar{\tau} \equiv(E-\alpha+\beta \bar{w}) / \beta$ is the prohibitive tariff, and with $P_{m}^{\cdot}\left(\tau^{*}\right)$ and $P_{x}^{*}(\tau)$ defined symmetrically. Finally, domestic welfare is measured as the sum of consumer surplus, producer surplus, and tariff revenue in the import sector, and consumer and producer surplus in the export sector, or

$$
\begin{aligned}
W\left(\tau, \tau^{*}\right)=\int_{P_{m}(\tau)}^{\alpha / \beta}(\alpha-\beta P) d P & +\int_{\bar{w} /(1+\gamma)}^{P_{m}(\tau)} e d P+\tau\left[E-\left(\alpha-\beta P_{x}^{*}(\tau)\right)\right] \\
& +\int_{P_{x}\left(\tau^{*}\right)}^{\alpha / \beta}(\alpha-\beta P) d P+\int_{0}^{P_{x}\left(\tau^{*}\right)} E d P
\end{aligned}
$$

with foreign welfare $W^{*}\left(\tau^{*}, \tau\right)$ defined symmetrically.

\section{A. Static Tariff Setting}

1 am now ready to derive each country's optimal tariff. For simplicity in what follows. 1 restrict my attention to situations where a country's optimal tariff leads to import prices of 
$\bar{w}$, i.e., prices which would bring a portion of the (infinitely elastically supplied) rest-ofeconomy labor force into the import-competing sector. This amounts to a restriction on the maximum size of e and $\gamma$, in particular that

$$
e<\frac{\alpha}{2}-\frac{1+3 \gamma}{2(1+\gamma)} \beta \bar{w}
$$

Under (7), a country's optimal tariff will be equivalent to that which maximizes tariff revenue, and is given by

$$
\tau_{m}=\frac{E-\alpha+\beta \bar{w}}{2 \beta}=\bar{\tau} / 2 \text {. }
$$

Moreover, with the two goods markets independent and with export taxes ruled out by assumption, optimal tariff choices are independent of the tariff choices of one's trading partner, as (8) indicates. Thus, defining the static tariff game to be the game in which each country simultaneously selects an import tariff to maximize its own welfare, the Nash equilibrium of the static tariff game occurs when each country selects

$$
\hat{\tau}^{N}=\bar{\tau} / 2 \text {. }
$$

Despite the simplicity of this set-up, it still yields the essential elements that 1 will need to study the process of cooperative trade liberalization. In particular, it is readily established using (6) that $W\left(\tau=\tau^{\prime}, \tau^{*}=\tau^{\prime}\right)$ is strictly decreasing in $\tau^{\prime}$ for $\tau^{\prime} \epsilon(0, \bar{\tau})$, so that the static tariff game leads to a Prisoners' Dilemma: both countries are better off with symmetric free trade. and monotonically better off with any symmetric move toward free trade, but in 
the Nash equilibrium both countries impose positive tariffs and suffer the consequent drop in welfare.

This is illustrated in Figure 2, where the domestic gains from trade associated with the import and export good are depicted in the top left and right panel, respectively, and the lower panel depicts domestic and foreign tariff reaction curves. Under reciprocal free trade, the gains from trade for the domestic country amount to the area under its import demand curve $\left(m_{1} m_{2} m_{6} m_{7}\right.$ in the top left panel) and the area above its export supply curve $\left(x_{1} x_{3} x_{5}\right.$ in the top right panel). Under the domestic optimal tariff, the additional gains from importing are given by the net tariff revenue collected from abroad minus the dead weight loss $\left(m_{2} m_{3} m_{4} m_{5}\right.$ minus $m_{5} m_{6} m_{7} m_{8}$ in the top left panel). Facing the optimal tariff abroad, the reduction in the gains from exporting are given by the net import taxes paid to exporters and the dead weight loss $\left(x_{1} x_{2} x_{4} x_{7}\right.$ plus $x_{7} x_{4} x_{5} x_{6}$ in the top right panel). Taken together, when both countries impose their optimal tariffs, the losses in each country's export market outweigh the gains in its import market, with the net loss for the domestic country amounting to the sum of the dead weight losses it incurs in each market $\left(m_{5} m_{6} m_{7} m_{8}\right.$ plus $\left.x_{7} x_{4} x_{5} x_{6}\right)$. The lower panel of Figure 2 depicts domestic and foreign lariff reaction curves, with domestic indifference curves reflecting the relative welfare rankings associated with reciprocal free trade, unilateral optimal tariff setting, and Nash equilibrium tariffs in the static tariff game.

\section{B. Dynamic Tariff Setting}

Suppose now that, starting from their Nash tariffs, countries were given the opportunity to cooperate in tariff policy, subject only to the condition that this cooperation be self-enforcing. Such an opportunity might arise with the establishment of an international 
organization such as GATT, which has the ability to coordinate multilateral reductions in tariffs but no independent ability to enforce the agreed-upon reductions. 1 analyze such an opportunity by considering now a stationary dynamic tariff game, which is defined by the infinite repetition of the static tariff game just described. 1 refer to this games as stationary because none of the model's parameters change through time. In particular, I maintain the assumption for now that import-competing workers who choose to leave the import-competing sector as a result of falling levels of protection nevertheless maintain their $\gamma$ units of importcompeting sector-specific skill if ever they wish to return to the import-competing sector. 1 focus on a particular class of subgame perfect equilibria for the stationary dynamic tariff game, in which (i) in equilibrium, the two countries select the same import tariff in each period, and (ii) if a deviation from this common tariff occurs, then in the next period and forever after, countries revert to the Nash equilibrium tariffs of the static tariff game. 1 define the most-cooperative equilibrium of the stationary dynamic game as the subgame perfect equilibrium which yields the lowest possible equilibrium tariff while satisfying (i) and (ii). The corresponding tariff is called the most-cooperative tariff for the stationary dynamic tariff game. $^{2}$

In a dynamic model, countries have the possibility of supporting a cooperative tariff, $\tau^{c}<\hat{\tau}^{N}$, since any attempt to raise one's current-period tariff will be met with the retaliatory

2 Forms of punishment other than infinite Nash reversion might be considered, some of which could support greater levels of cooperation. However, the qualitative nature of the non-stationary behavior of cooperative tariffs derived below is unlikely to be affected. Morcover, infinite reversion is not entirely implausible as a representation of actual tariff wars. As one example, the high U.S. tariffs on imports of light-duty trucks imposed as a rcsult of thc "chicken war" with the European Community in 1963 are still in place 30 years later. 
(Nash) tariff from one's trading partner in future periods. Thus, a cooperative tariff $\tau^{c}$ can be supported in an equilibrium for the stationary dynamic tariff game if the one-time incentive to cheat is sufficiently small relative to the future value of maintaining a cooperative relationship with one's trading partner.

If a country cheats, it will deviate from $\tau^{c}$ and select its best-response Nash tariff, $\hat{\tau}^{N}$. With this, the fundamental "no defect" condition which formalizes the intuition above can be written as

$$
W\left(\tau=\hat{\tau}^{N}, \tau^{*}=\tau^{c}\right)-W\left(\tau=\tau^{c}, \tau^{*}=\tau^{c}\right) \leq \frac{\delta}{1-\delta}\left[W\left(\tau=\tau^{c}, \tau^{*}=\tau^{c}\right)-W\left(\tau=\hat{\tau}^{N}, \tau^{*}=\hat{\tau}^{N}\right)\right]
$$

where $\delta \epsilon(0,1)$ is the discount factor between periods. It will be convenient in what follows to write this condition in the slightly different form of

$$
W\left(\tau=\tau^{c}, \tau^{*}=\tau^{c}\right) \geq(1-\delta) W\left(\tau=\hat{\tau}^{N}, \tau^{*}=\tau^{c}\right)+\delta W\left(\tau=\hat{\tau}^{N}, \tau^{*}=\hat{\tau}^{N}\right) \equiv V\left(\tau^{*}=\tau^{c}, \delta\right)
$$

The right-hand-side of $(11)$, which I denote by $V\left(\tau^{*}=\tau^{c}, \delta\right)$, is decreasing in $\tau^{c}$ for $\delta<1$ and $\tau^{c}<\hat{\tau}^{N}$, and decreasing in $\delta$ for $\tau^{c}<\hat{\tau}^{N}$ because a country's welfare is decreasing in the tariff of its trading partner.

In what follows, I will be interested in cases where the most cooperative tariff satisfying (1I) leads to the relocation of at least some of the e import-competing workers, all of whom by (7) are content to stay in the import-competing sector under $\dot{\tau}^{N}$. This requires that the equilibrium domestic import price under the most cooperative tariff be equal to $\bar{w} /(1+\gamma)$ which, according to (4), implies that the most cooperative tariff must satisfy 


$$
\tau<e / \beta \equiv \tau
$$

This will amount to a restriction on the minimal size of $\delta$ which I will characterize momentarily. Under the restriction (12), it is easily checked from (6) that

$$
\begin{aligned}
& W\left(\tau=\tau^{c}, \tau^{*}=\tau^{c}\right)=\beta\left[\left(\frac{\alpha}{\beta}\right)^{2}-\left(\frac{\bar{W}}{1+\gamma}\right)^{2}-\frac{\left(\tau^{c}\right)^{2}}{2}\right] \\
& W\left(\tau=\hat{\tau}^{N}, \tau^{*}=\hat{\tau}^{N}\right)=\beta\left[\left(\frac{\alpha}{\beta}\right)^{2}-\frac{1-\gamma}{1+\gamma}(\bar{w})^{2}+\frac{\gamma}{1+\gamma} \frac{e \bar{W}}{\beta}-\frac{(\bar{\tau})^{2}}{8}\right] \\
& W\left(\tau=\hat{\tau}^{N}, \tau^{*}=\tau^{c}\right)=\beta\left(\left(\frac{\alpha}{\beta}\right)^{2}+\frac{\gamma^{2}+2 \gamma-2}{2(1+\gamma)^{2}}(\bar{w})^{2}+\frac{\gamma}{1+\gamma} \frac{\bar{w}}{\beta}(e-\alpha)+\frac{(\bar{\tau})^{2}}{4}\right. \\
& \left.-\left(\frac{\alpha}{\beta}-\frac{\bar{w}}{1+\gamma}\right) \tau^{c}+\frac{\left(\tau^{c}\right)^{2}}{2}\right]
\end{aligned}
$$

The determination of the most-cooperative tariff $\hat{\tau}_{s}^{c} \in[0, \bar{\tau}]$ is now illustrated in Figure

3. From (13), $W\left(\tau=\tau^{c}, \tau^{*}=\tau\right.$ ) is decreasing and concave in $\tau^{c}$ over $\tau^{c} \in[0, \bar{\tau}]$, while from

(11), (14) and (15), $V\left(\tau^{*}=\tau^{c}, \delta\right)$ is decreasing and convex in $\tau^{c}$ over this range. For $\delta=1, V\left(\tau^{*}=\tau^{c}, \delta\right)=W\left(\tau=\hat{\tau}^{N}, \tau^{*}=\hat{\tau}^{N}\right)$ and $V\left(\tau^{*}=\tau^{c}, \delta\right)$ must intersect the $y$-axis of Figure 3 below $W(\tau=0, \tau=0)$. For $\delta$ of this magnitude, free trade can be supported in the stationary dynamic game, since the incentive constraint (11) is met with strict inequality for $\tau=\tau^{*}=0$. As $\delta$ is reduced from $1, V\left(\tau^{\circ}=\tau^{c}, \delta\right)$ shifts up in Figure 3, and its intersection with the $y$-axis rises above $W\left(\tau=\hat{\tau}^{N}, \tau^{*}=\hat{\tau}^{N}\right)$. The critical $\bar{\delta}$ below which free trade cannot be supported is defined implicitly by $W\left(\tau=0, \tau^{*}=0\right)=V\left(\tau^{\circ}=\tau^{c}=0, \bar{\delta}\right)$. As $\delta$ is reduced from $\bar{\delta}, V\left(\tau^{*}=\tau^{c}, \delta\right)$ 
continues to shift up in Figure 3, and its intersection with $W\left(\tau=\tau^{c}, \tau^{*}=\tau\right)$ yields monotonically increasing values for $\hat{\tau}_{s}^{c}$. It can be shown that there exists a critical $\bar{\delta}<\bar{\delta}$ defined implicitly by $W\left(\tau=\tilde{\tau}, \tau^{*}=\tilde{\tau}\right)=V\left(\tau^{*}=\tau^{c}=\tilde{\tau}, \tilde{\delta}\right)$ such that the most cooperative tariff in the stationary dynamic game with discount factor $\tilde{\delta}$ is $\hat{\tau}_{s}^{c}=\bar{\tau}$. Figure 3 , then, depicts the determination of $\hat{\tau}_{s}^{c} \in(0, \tilde{\tau})$ under the assumption that $\delta \epsilon(\tilde{\delta}, \bar{\delta})$.

In what follows, I concentrate on discount factors in this range, because I am interested in trade liberalization which (i) would induce some of the resources originally located in the import-competing sector to relocate (which requires $\delta>\tilde{\delta}$ ) and, (ii) cannot be "completed" in a single "round" of tariff cuts (which requires $\delta<\bar{\delta}$ ). The next section introduces non-stationarity into the model in an attempt to remove the quotes from (ii) above.

\section{A Non-Stationary Model of Trade Liberalization}

The movement from $\hat{\mathfrak{t}}^{N}$ to $\hat{\tau}_{s}^{c}$ illustrated in Figure 3 could be thought of as representing the process of trade liberalization that comes about when countries move from a non-cooperative to a cooperative trading regime. The problem is, it's not much of a process. or at least not one that ought to take any time.

However, the elements of a non-trivial process of trade liberalization, with current liberalization setting up the prospects for further liberalization sometime in the future, do 
suggest themselves if one considers the impact of a drop in the supply of import-competing workers (e) on the sustainable stationary cooperative tariff $\hat{\tau}_{s}^{c}$. Using (13), (14), and (15), defining $\bar{\tau}_{i} \equiv e_{i} / \beta$ in analogy with (12), and referring to Figure $3, W\left(\tau=\tau^{c}, \tau^{\circ}=\tau\right)$ is unaffected by a change from $e_{1}$ to $e_{2}, e_{1}>e_{2}$, for $\tau^{c} \in\left[0, \bar{\tau}_{2}\right]$ while $V\left(\tau^{*}=\tau^{c}, \delta\right)$ would shift down with the drop in e, leading to a fall in $\hat{\mathfrak{\tau}}_{s}^{c}$. Recalling that $K$ ) is simply a weighted average of welfare under defection and under Nash punishments, the downward shift in $V($ ) as e drops reflects the fact that high tariffs become less desirable as their capacity to generate rents diminishes.

Thus, in this stationary dynamic model, resources in the import-competing sector that are (or could potentially be) earning rents from their sector-specific skills limit the degree of attainable trade liberalization. The intuition for this result is that, by being able to transform into rents a portion of what otherwise would have been dead weight loss under a tariff hike, the presence of such resources makes deviation from a low cooperative tariff to a high tariff more desirable for the deviating country, and makes punishments under reciprocally high tariffs less painful. But this in turn suggests that liberalization, which leads to the relocation of some of the existing import-competing workers, might eventually feed back upon itself and pave the way for further liberalization, if the workers who leave the import-competing sector eventually see their industry-specific skills from the import-competing sector--and hence their ability to earn rents in the sector should the government retum to a higher tariff--depreciate over time from lack of use. This is the logic underlying what follows. 
I now assume that each country's import-competing sector begins with $e_{1} /(1+\gamma)$

workers, each of whom owns 1 unit of effective labor equally efficient in either the importcompeting or rest-of-economy sector, and $\gamma$ units of effective labor tailored for use only in the import-competing sector. In any period, after observing the foreign and domestic tariff choices for that period, any worker currently in the import-competing sector may choose to leave the sector and work in the rest-of-the-economy sector where he would receive the market wage $\bar{w}$. However, should a worker choose to leave the import-competing sector, then in every period that he is gone from the import-competing sector, there is a constant probability $\lambda$ that his specific skill in the import-competing sector will depreciate to zero. Once this depreciation occurs, the worker's effectiveness in the import-competing sector becomes like that of all other workers currently in the rest of the economy, and he amounts to 1 unit of effective labor in either the import-competing or rest-of-the-economy sectors. I assume that the possibility of skill depreciation occurs at the beginning of each period; that all workers currently in the rest-of-the-economy sector who ended the previous period with their import-competing skills in tact either loose or keep their $\gamma$ units of import-competing skill together; that whether these workers keep or loose their skills becomes common knowledge immediately after it is determined; that, after observing this, foreign and domestic governments then set tariffs for the period simultaneously; and that, observing those tarifr choices, workers then choose where to locate for the period's production.

If equilibrium protection in the import-competing sector moved non-monotonically through time, an import-competing worker's sectoral location decision would now involve 
potentially complex intertemporal calculations, since the possibility of sector-specific skill depreciation while outside the import-competing sector creates an option value to staying in the sector. To avoid this complication I will stick to cases of monotonic trade liberalization, leaving nonmonotonic movements as an interesting area for future work.

In order to characterize this nonstationary model, I now define the state of the importcompeting sector by the effective import-competing labor supply, e, remaining in the economy at a point in time, i.e., the effective labor force in the economy that, at a moment in time, still retains the import-competing skill. Let $i=1,2, \ldots$ index the history of states, so that $e_{1}$ denotes the initial state of the import-competing sector, and $e_{i}$ denotes the state after $i-1$ episodes of skill depreciation. By an episode of skill depreciation, I am referring to a period in which the most recent cohort of import-competing workers who have chosen to work outside the import-competing sector as a result of the preceding "round" of liberalization lose their sector-specific skills.

In analyzing this non-stationary dynamic tariff game, 1 then examine a class of subgame perfect equilibria in which (i) along the equilibrium path, and for any given state of the import-competing sector, the foreign and domestic countries select a common import tariff $\tau_{i}^{c}$ at all dates associated with that state; and (ii) if at any point in the game a deviation from the equilibrium tariff for the corresponding state occurs, then in the next period and forever thereafter the two countries revert to the Nash equilibrium tariffs of the static tariff game.

To solve this non-stationary model recursively, 1 will restrict my attention to cases in which free trade is achievable in a finite number of states, or "rounds" of liberalization, with 
the number denoted by $n^{3}$ Once again, this amounts to a restriction on the minimum value of $\delta$ for a given $e_{1}$, and it ensures that $e_{i}$ will also satisfy (12) for each $i=1,2, \ldots, n-1$ (if $e_{i}$ didn't satisfy (12) for $i \in\{1,2, \ldots n-1\}$, then liberalization would end after the $i^{\text {th }}$ round with a positive tariff). Given this, I look for the most-cooperative equilibrium, and solve for the corresponding most-cooperative liberalization path, $\left(\hat{\tau}_{1}^{c}, \hat{\tau}_{2}^{c}, . . \hat{\tau}_{n}^{c}\right)$, in a recursive fashion starting with round $n-1$ and requiring that each incentive constraint bind back to round 1 .

As before I restrict $e_{1}$ to satisfy (7). Since $e_{i>1}$ can only decline from $e_{1}$ (I do not allow workers to obtain the import-competing skill if they don't have it, nor would they have an equilibrium incentive to do so), this means that the Nash tariff, to which a country would defect if it so chose and to which both countries would revert after a defection, is stateinvariant and continues to be defined by (8). Finally, note that, given these restrictions and the monotonic liberalizations on which I focus, import-competing workers who contemplate leaving the import-competing sector in a given period need only base their equilibrium decision on that period's tariff choices, since equilibrium tariffs will only fall in subsequent periods.

I now need to distinguish between the effective supply of workers with importcompeting skills who are employed in the import-competing sector and the economy-wide effective supply of such workers $\left(e_{i}\right)$. Denoting by $\epsilon_{i}$ the effective force of workers with

${ }^{3}$ Hence, for a period in state $i$, the $i^{\text {h }}$ round of liberalization has occurred, and governments are waiting for the state to change, i.e., for an episode of skill depreciation, so that the $i^{\text {ih }}+1$ round can proceed. 
import-competing skills that choose to remain in the import-competing sector for a given period in state $i$ after domestic and foreign governments have set their tariffs for the period, it is direct to calculate that

$$
\epsilon_{i}=\beta \tau_{i}^{c} \quad i=1,2, \ldots, n
$$

along the equilibrium path. Moreover, since these $\epsilon_{i}$ workers will be the only ones to retain their import-competing skills when the state of the import-competing sector advances to $i+1$, i.e., when the skills of the $e_{i}-\epsilon_{i}$ workers who chose to leave the import-competing sector as a result of the liberalization in round $\mathrm{i}$ depreciate, they define that state:

$$
e_{i+1}=\epsilon_{i} \quad i=1,2, \ldots, n-1
$$

Substituting (16) into (17) yields

$$
e_{i+1}=\beta \tau_{i}^{c} \quad i=1,2, \ldots, n-1
$$

While (16) and (18) depict the allocational decisions of import-competing workers and the state of the import-competing sector as a function of current and lagged equilibrium tariffs, respectively, I also need to consider the behavior of workers if either country were to deviate from the equilibrium tariff $\tau_{i}^{c}$ and play $\hat{\tau}^{N}$. If workers observed a government playing $\hat{\tau}^{N}$, then all workers with import-competing skills in the deviating country would retum to enjoy the rents in that period and in all future periods. However, all workers with import-competing skills in the other (non-deviating) country might not retum in that period to the import-competing sector, since their government is still (for that period) playing a low 
cooperative tariff at which they can not all earn the reservation wage. However, if these workers choose not to return until their government reverts to $\hat{\tau}^{N}$ next period, they risk loosing their import-competing skills. In what follows, 1 assume that this latter effect dominates, so that in the event that either country is observed to play $\hat{t}^{N}$, all importcompeting workers with import-competing skills in both countries return to their importcompeting sector. This assumption allows me to avoid asymmetries across countries that would add further to the complexity of the problem, but the assumption is otherwise inessential. 1 thus have

$$
\epsilon_{i}=e_{i} \text { if } \tau=q^{N} \text { and/or } \tau^{*}=\hat{\tau}^{N} \text {. }
$$

Now consider the welfare associated with the various tariff choices. In the stationary model of the previous section I defined $W\left(\tau=\tau^{c}, \tau^{*}=\tau\right), W\left(\tau=\hat{\tau}^{N}, \tau^{*}=\hat{\tau}^{N}\right)$, and $W\left(\tau=\hat{\tau}^{N}, \tau^{*}=\tau\right)$ in (13), (14), and (15), respectively. In that model, e played the role of $e_{i}$ in the present setting. Everything else is the same. Thus, using (13), (14), (15), (18) and (19), I have

$$
\begin{gathered}
W_{i}\left(\tau=\tau_{i}^{c}, \tau^{*}=\tau_{i}^{c}\right)=\beta\left[\left(\frac{\alpha}{\beta}\right)^{2}-\left(\frac{\bar{w}}{1+\gamma}\right)^{2}-\frac{\left(\tau_{i}^{c}\right)^{2}}{2}\right] \equiv W_{i}\left(\tau_{i}^{c}, \tau_{i}^{c}\right) \\
\begin{aligned}
W_{i}\left(\tau=\tau^{N}, \tau^{*}=\tau^{N}, e_{i}\left(\tau_{i-1}^{c}\right)\right)=\beta\left[\left(\frac{\alpha}{\beta}\right)^{2}-\frac{1-\gamma}{1+\gamma}(\bar{w})^{2}+\frac{\gamma}{1+\gamma} \frac{\bar{w}}{\beta} e_{i}\left(\tau_{i-1}^{c}\right)\right. \\
\left.-\frac{(\bar{\tau})^{2}}{8}\right] \equiv W_{i}\left(\hat{\tau}^{N}, \hat{\tau}^{N}, \tau_{i-1}^{c}\right)
\end{aligned}
\end{gathered}
$$




$$
\begin{aligned}
W_{i}\left(\tau=\hat{\tau}^{N}, \tau^{+}\right. & \left.=\tau_{i}^{c}, e_{i}\left(\tau_{i-1}^{c}\right)\right)=\beta\left[\left(\frac{\alpha}{\beta}\right)^{2}+\frac{\left(\gamma^{2}+2 \gamma-2\right)}{2(1+\gamma)^{2 l}} \bar{w}\right)^{2}+\frac{\gamma}{1+\gamma} \frac{\bar{w}}{\beta}\left(e_{i}\left(\tau_{i-1}^{c}\right)-\alpha\right) \\
& \left.+\frac{(\bar{\tau})^{2}}{4}-\left(\frac{\alpha}{\beta}-\frac{\bar{w}}{1+\gamma}\right) \tau_{i}^{c}+\frac{\left(\tau_{i}^{c}\right)^{2}}{2}\right]=W_{i}\left(\hat{\tau}^{N}, \tau_{i}^{c}, \tau_{i-1}^{c}\right)
\end{aligned}
$$

To derive the incentive constraint analogous to $(10)$, I now define $Z_{\mathrm{j}}$, the discounted welfare under cooperative tariffs into the infinite future as viewed from a period in state $i$, by

$$
\begin{aligned}
z_{i} \equiv & \delta \lambda\left(w_{i+1}\left(\tau_{i+1}^{c}, \tau_{i+1}^{c}\right)+\delta \lambda\left(w_{i+2}\left(\tau_{i+2}^{c}, \tau_{i+2}^{c}\right)\right.\right. \\
& \left.+\delta \lambda\left(w_{i+1}\left(\tau_{i+3}^{c}, \tau_{i+1}^{c}\right)+\ldots\right\}+\delta(1-\lambda)\left(w_{i+2}\left(\tau_{i+2}^{c}, \tau_{i+2}^{c}\right)+\ldots\right\}\right) \\
& +\delta(1-\lambda)\left(w_{1+1}\left(\tau_{i+1}^{c}, \tau_{i+1}^{c}\right)+\delta \lambda\left(w_{i+2}\left(\tau_{i+2}^{c}, \tau_{i+2}^{c}\right)+\ldots\right\}\right. \\
& \left.+\delta(1-\lambda)\left(w_{i+1}\left(\tau_{i+1}^{c}, \tau_{i+1}^{c}\right)+\ldots \mid\right\}\right)+\delta(1-\lambda)\left(w_{i}\left(\tau_{i}^{c}, \tau_{i}^{c}\right)\right. \\
& +\delta \lambda\left(w_{i+1}\left(\tau_{i+1}^{c}, \tau_{i+1}^{c}\right)+\delta \lambda\left(w_{i+2}\left(\tau_{i+2}^{c}, \tau_{i+2}^{c}\right)+\ldots\right\}\right. \\
& +\delta(1-\lambda)\left(w_{i+1}\left(\tau_{i+1}^{c}, \tau_{i+1}^{c}\right)+\ldots \mid\right)+\delta(1-\lambda)\left(w_{i}\left(\tau_{i}^{c}, \tau_{i}^{c}\right)\right. \\
& +\delta \lambda\left(w_{i+1}\left(\tau_{i+1}^{c}, \tau_{i+1}^{c}\right)+\ldots 1+\delta(1-\lambda)\left(w_{i}\left(\tau_{i}^{c}, \tau_{i}^{c}\right)+\ldots \mid\right\}\right)
\end{aligned}
$$

where 1 adopt the convention that $\tau_{i+j}^{c}=\tau_{n}^{c}$ and $W_{i+j}=W_{n}$ for $\mathrm{j} \geq \mathrm{n}-\mathrm{i}$. The incentive constraint for $\tau_{i}^{c}, i \in\{1, \ldots, n\}$ is then

$$
W_{i}\left(\hat{\tau}^{N}, \tau_{i}^{c}, \tau_{i-1}^{c}\right)-W_{i}\left(\tau_{i}^{c}, \tau_{i}^{c}\right) \leq Z_{i}-\frac{\delta}{1-\delta} W_{i}\left(\hat{\tau}^{N}, \hat{\imath}^{N}, \tau_{i-1}^{c}\right)
$$

Starting with round $n,(23)$ defines the range of $\tau_{n-1}^{c}$ that is consistent with $\hat{\tau}_{n}^{c}\left(\tau_{n-1}^{c}\right)=0$. For $i=n$, future tariffs are stationary (at zero) along the equilibrium path, and $Z_{n}$ is simply $\frac{\delta}{1-\delta} W_{n}\left(\tau_{n}^{c}=0, \tau_{n}^{c}=0\right)$. Thus, (23) becomes 


$$
W_{n}\left(\hat{\tau}_{n}^{c}=0, \hat{\tau}_{n}^{c}=0\right) \geq(1-\delta) W_{n}\left(\hat{\imath}^{N}, \hat{\tau}_{n}^{c}=0, \tau_{n-1}^{c}\right)+\delta W_{n}\left(\hat{\imath}^{N}, \hat{\tau}^{N}, \tau_{n-1}^{c}\right)
$$

Using (24), and noting that the left-hand side of (24) is independent of $\tau_{n-1}^{c}$ while the righthand side is increasing in $\tau_{n-1}^{c}, \tau_{n}^{c}\left(\tau_{n-1}^{c}\right)=0$ is attainable for $\tau_{n-1}^{c} \in\left[0, \overline{\tau_{n-1}^{c}}\right]$, with $\overline{\tau_{n-1}^{c}}$ defined implicitly by

$$
W_{n}\left(\hat{\tau}_{n}^{c}=0, \hat{\tau}_{n}^{c}=0\right)=(1-\delta) W_{n}\left(\hat{\imath}^{N}, \hat{\imath}_{n}^{c}=0, \overline{\tau_{n-1}^{c}}\right)+\delta W_{n}\left(\hat{\imath}^{N}, \hat{\tau}^{N}, \overline{\tau_{n-1}^{c}}\right)
$$

To characterize the most-cooperative tariff for earlier rounds, it is useful to rewrite the incentive constraint in an altemative form:

$$
\begin{aligned}
& W_{i}\left(\hat{\tau}^{N}, \tau_{i}^{c}, \tau_{i-1}^{c}\right)-W_{i}\left(\tau_{i}^{c}, \tau_{i}^{c}\right) \leq \\
& {\left[\frac{\delta}{1-\delta(1-\lambda)}\right]\left((1-\lambda) W_{i}\left(\tau_{i}^{c}, \tau_{i}^{c}\right)+\lambda\left[W_{i+1}\left(\tau_{i+1}^{c}, \tau_{i+1}^{c}\right)+z_{i+1}\right]\right\} } \\
&-\frac{\delta}{1-\delta} W_{i}\left(\hat{\imath}^{N}, \hat{\imath}^{N}, \tau_{i-1}^{c}\right)
\end{aligned}
$$

With some manipulation, (25) can be shown to be equivalent to (23). For $\mathrm{i}=\mathrm{n}-1,(25)$ becomes

$$
\begin{aligned}
W_{n-1}\left(\tau_{n-1}^{c}, \tau_{n-1}^{c}\right) \geq & {\left[\frac{1-\delta(1-\lambda)}{1-\delta}\right]\left[(1-\delta) W_{n-1}\left(\hat{\tau}^{N}, \tau_{n-1}^{c}, \tau_{n-2}^{c}\right)+\delta W_{n-1}\left(\hat{\tau}^{N}, \hat{\tau}^{N}, \tau_{n-2}^{c}\right)\right] } \\
& -\frac{\delta \lambda}{1-\delta} W_{n}\left(\hat{\tau}_{n}^{c}=0, \hat{\vartheta}_{n}^{c}=0\right)
\end{aligned}
$$

Using (26), and noting that the left-hand side of (26) is independent of $\tau_{n-2}^{c}$ while the righthand side is increasing in $\tau_{n-2}^{c}$, the maximum $\tau_{n-2}^{c}$ consistent with $\hat{\tau}_{n}^{c}\left(\hat{\tau}_{n-1}^{c}\left(\tau_{n-2}^{c}\right)\right)=0$, denoted by $\overline{\tau_{n-2}^{c}}$, is defined implicitly by 


$$
\begin{aligned}
W_{n-1}\left(\overline{\tau_{n-1}^{c}}, \overline{\tau_{n-1}^{c}}\right)= & {\left[\frac{1-\delta(1-\lambda)}{1-\delta}\right]\left((1-\delta) W_{n-1}\left(\hat{\tau}^{N}, \overline{\tau_{n-1}^{c}}, \overline{\tau_{n-2}^{c}}\right)+\delta W_{n-1}\left(\hat{\tau}^{N}, \hat{\tau}^{N}, \overline{\tau_{n-2}^{c}}\right)\right\} } \\
& -\frac{\delta \lambda}{1-\delta} W_{n}\left(\hat{\tau}_{n}^{c}=0, \hat{\tau}_{n}^{c}=0\right)
\end{aligned}
$$

Then for $\tau_{n-2}^{c} \epsilon\left[\overline{\tau_{n-1}^{c}, \tau_{n-2}^{c}}\right], \quad \hat{\tau}_{n-1}^{c}\left(\tau_{n-2}^{c}\right)$ is defined by

$$
\begin{aligned}
W_{n-1}\left(\hat{\imath}_{n-1}^{c}, \hat{\tau}_{n-1}^{c}\right)= & {\left[\frac{1-\delta(1-\lambda)}{1-\delta}\right]\left[(1-\delta) W_{n-1}\left(\hat{\imath}^{N}, \hat{\imath}_{n-1}^{c}, \tau_{n-2}^{c}\right)+\delta W_{n-1}\left(\hat{\imath}^{N}, \hat{\imath}^{N}, \tau_{n-2}^{c}\right)\right] } \\
& -\frac{\delta \lambda}{1-\delta} W_{n}\left(\hat{\imath}_{n}^{c}=0, \hat{\imath}_{n}^{c}=0\right)
\end{aligned}
$$

Since the right-hand side of (27) is increasing in $\tau_{n-2}^{c}$ while the left-hand side is independent of $\tau_{n-2}^{c}$, and since at $\hat{\tau}_{n-1}^{c}$ the right-hand side of (27) must decline in $\tau_{n-1}^{c}$ at a faster rate than the left hand side of (27), $\hat{\tau}_{n-1}^{c}\left(\tau_{n-2}^{c}\right)$ is increasing in $\tau_{n-2}^{c}$.

Finally, for $i \epsilon\{n-2, \ldots 1\}, I$ use the fact that (23) must hold with equality at $\hat{\tau}_{i}^{c}\left(\tau_{i-1}^{c}\right)$ for $i \epsilon\{n-1, \ldots, 1\}$ along the equilibrium most-cooperative liberalization path. Thus, evaluating (23) for $i+1$ at $\hat{\tau}_{i+1}^{c}\left(\tau_{i}^{c}\right)$, multiplying both sides by $\frac{\delta \lambda}{1-\delta(1-\lambda)}$, and subtracting it from (25) for $i$,

with $i \epsilon\{n-2, \ldots, 1\}$, yields 


$$
\begin{aligned}
W_{i}\left(\tau_{i}^{c}, \tau_{i}^{c}\right) & \geq\left[\frac{1-\delta(1-\lambda)}{\delta(1-\lambda)}\right]\left[W_{i}\left(\hat{\tau}^{N}, \tau_{i}^{c}, \tau_{i-1}^{c}\right)-W_{i}\left(\tau_{i}^{c}, \tau_{i}^{c}\right)+\frac{\delta}{1-\delta} W_{i}\left(\hat{\tau}^{N}, \tau^{N}, \tau_{i-1}^{c}\right)\right] \\
& -\frac{\lambda}{1-\lambda}\left[W_{i+1}\left(\hat{\tau}^{N}, \tau_{i+1}^{c}\left(\tau_{i}^{c}\right), \tau_{i}^{c}\right)+\frac{\delta}{1-\delta} W_{i+1}\left(\hat{\tau}^{N}, \hat{\tau}^{N}, \tau_{i}^{c}\right)\right] \\
& \equiv U_{i}\left(\tau_{i}^{c}, \tau_{i-1}^{c}\right)
\end{aligned}
$$

for $i \epsilon\{n-2, \ldots, 1\}$. Starting with $i=n-2$ and working back to $i=1$, I can then define $\hat{\tau}_{i}^{c}\left(\tau_{i-1}^{c}\right)$ by

$$
W_{i}\left(\tau_{i}^{c}, \tau_{i}^{c}\right)=U_{i}\left(\tau_{i}^{c}, \tau_{i-1}^{c}\right) \text { for } \tau_{i-1}^{c} \epsilon\left[\overline{\tau_{i}^{c}}, \overline{\tau_{i-1}^{c}}\right]
$$

with $\overline{\tau_{i-1}^{c}}$ defined by

$$
W_{1}\left(\overline{\tau_{i}^{c}}, \overline{\tau_{i}^{c}}\right)=U_{i}\left(\overline{\tau_{i}^{c}}, \overline{\tau_{i-1}^{c}}\right)
$$

Again, since $U_{i}()$ is increasing in $\tau_{i-1}^{c}$ while $W_{i}\left(\tau_{i}^{c}, \tau_{i}^{c}\right)$ is independent of $\tau_{i-1}^{c}$, and since at $\hat{\tau}_{i}^{c}, U_{l}()$ must decline in $\tau_{i}^{c}$ at a faster rate than $W_{i}\left(\tau_{i}^{c}, \tau_{i}^{c}\right), \hat{\tau}_{i}^{c}\left(\tau_{i-1}^{c}\right)$ is increasing in $\tau_{i-1}^{c}$, as Figure 4 depicts. It can also be shown that

$$
\tau_{i}^{c}\left(\overline{\tau_{i-1}^{c}}\right)=\hat{\tau}_{i-1}^{c}\left(\overline{\tau_{i-1}^{c}}\right) \text { for } i \in\{2, \ldots, n\}
$$

This ensures that $\hat{\tau}_{i}^{c}\left(\tau_{i-1}^{c}\right)$ is continuous over the entire interval $\left[0, \overline{\tau_{0}^{c}}\right]$.

Figure 5 depicts the most-cooperative trade liberalization path starting from a tariff $\tau_{0}$, under the assumption that free trade is achievable from $\tau_{0}$ in $n$ rounds of liberalization. The left hand quadrant depicts $\hat{\tau}_{l}^{c}\left(\tau_{l-1}^{c}\right)$ as a continuous and increasing function lying below the 
45 line. The figure illustrates a $\tau_{0}$ which can be liberalized in 6 rounds. The right hand quadrant displays the most-cooperative path of liberalization, starting from $\tau_{0}$, that is implied by $\hat{\tau}_{i}^{c}\left(\tau_{i-1}^{c}\right)$. The initial liberalization from $\tau_{0}$ to $\hat{\tau}_{1}^{c}$ induces a portion of the importcompeting workers to leave the sector and move to the rest of the economy, where their import-competing skills are at risk of depreciating. Once their skills depreciate, and the workers lose their ability to seek rents in the import-competing sector in the event of a return to high tariffs, the enforcement issues associated with sustaining the tariff level $\hat{t}_{1}^{c}$ are mitigated, making possible the next round of liberalization, which results in tariff reductions

to $\hat{\tau}_{2}^{c}$. This round of liberalization induces a portion of the remaining import-competing workers to leave the sector and move to the rest of the economy, placing their importcompeting skills at risk of depreciating, and the process of liberalization continues.

\section{The 'Bicycle' Theory}

In the previous sections, I developed a model of trade liberalizing rounds in which the process of trade liberalization is gradual. All else equal, the greater the amount of rentgenerating resources that will be displaced when the liberalization is completed, the longer will be the process of liberalization, and the greater will be the number of rounds required to bring it about. In this section, I return to one of the central questions which motivated this paper, and examine the implications of the "failure" of a round for current levels of multilateral tariff cooperation. As discussed in the Introduction, there is a widely held view 
that failure to move forward in multilateral liberalization will not simply mean the end of further liberalization, but must lead as well to a retreat from present levels of cooperation. I now examine that view within the context of the model developed above. In particular, I ask whether the achievements of the previous round can be sustained in a period in which the (premature) end of the liberalization process becomes apparent.

In the model developed thus far, new rounds occur whenever import-competing workers who have left the import-competing sector as a result of the previous round's liberalization lose their import-specific skills, and hence lose their ability to earn rents in the import-competing sector in the event the government were to renege on the promise of low cooperative tariffs to which it agreed in the previous round. This reduction in the rentgenerating potential of tariff hikes relaxes the incentive constraint that defines the most cooperative tariff in any period, and allows countries to liberalize further.

I now introduce the assumption that both governments must also have the "political will" to engage in a new round of tariff liberalization: without this political will, the slack created in the incentive constraint by the process 1 have modeled above would go unused in supporting further liberalization. While admittedly ad hoc, the introduction of political will in this way allows me to consider the possibility that the necessary conditions for a successful round might one day fail to materialize. In particular, 1 assume that governments begin the process of liberalization in possession of this political will, but that in each period, after the state of the import-competing sector for the period is revealed, there is a constant probability $\rho$ that the political will for further liberalization in future rounds is permanently lost, and therefore that there will be no further liberalizing rounds in future periods, i.e., tariffs will 
remain stationary at the lowest level sustainable at that time. The timing of events and decisions in the rest of the period is otherwise as before: first the state of the import-sector is determined; then the state of political will is observed; then, governments set tariffs for the period; and finally, workers make their allocation decisions.

It is apparent that I can no longer restrict my focus to monotonic liberalizations, since the question I address now is whether a retreat from the progress of previous rounds is inevitable when it becomes known that future rounds are impossible. However, I continue to restrict my discussion to cases in which such a retreat, if it were indeed to occur, would be sufficiently small to leave some of the import-competing workers whose import skills remain intact still choosing to work outside the import-competing sector. This will ensure that, along the equilibrium path, domestic import-competing prices continue to be fixed at $\bar{w} /(1+\gamma)$, and therefore that workers' allocation decisions continue to depend only on the present-period's tariffs. ${ }^{4}$

Suppose, then, that with $\rho>0$ and fixed, the initial $e_{1}$ was such that the mostcooperative liberalization path would take n rounds to complete (reach free trade) if it did not end "prematurely" (if governments did not loose their "political will" before the last round was completed). I continue to define $\hat{\mathfrak{t}}_{i}^{c}$ as the most-cooperative tariff sustainable in the $i^{\text {th }}$ state of the import-competing sector, given that political will for further liberalization still

4 That is, I characterize cases where any equilibrium retreat from liberal trade policies is sufficiently small that it does not undo more liberalization than was achieved in the preceding round. This will ensure that workers who would care to reverse their allocation decisions and return to the import-competing sector are limited to those that were displaced by the preceding round and therefore still possess their import-competing skills. 
exists. With $\tau_{s i}^{\sigma}$ denoting the stationary cooperative tariff that can be supported in the event that the process of liberalization ends prematurely in state $i, \hat{\tau}_{s i}^{r}\left(\tau_{i-1}^{r}\right)$ is defined implicitly by the incentive constraint that must hold in a period when political will has been lost but the import-competing sector is still in state $\mathrm{i}$ :

$$
\begin{aligned}
W_{i}\left(\hat{\tau}^{N}, \tau_{s i}^{c}, \tau_{j-1}^{c}\right) & -W_{i}\left(\tau_{s i}^{c}, \tau_{s i}^{c}\right) \leq \frac{\delta}{1-\delta}\left[W_{i}\left(\tau_{s i}^{c}, \tau_{s i}^{c}\right)\right. \\
& \left.-W_{i}\left(\hat{\tau}^{N}, \hat{\tau}^{N}, \tau_{i-1}^{c}\right)\right] \equiv X_{i}\left(\tau_{s i}^{c}, \tau_{i-1}^{c}\right)
\end{aligned}
$$

Defining $K_{i}$ analogously to $Z_{i}$ in the previous section, the incentive constraint for $\tau_{i}^{\delta}, i \in\{1, \ldots n\}$, given that the import-competing sector is in state $\mathrm{i}$ and governments still maintain political will for further liberalization, is given by

$$
\begin{gathered}
W_{i}\left(\hat{\tau}^{N}, \tau_{i}^{c}, \tau_{i-1}^{c}\right)-W_{i}\left(\tau_{i}^{c}, \tau_{i}^{c}\right) \leq\left[\frac{\delta}{1-\delta(1-\lambda)(1-\rho)}\right](1-\lambda)(1-\rho) W_{i}\left(\tau_{i}^{c}, \tau_{i}^{c}\right) \\
+(1-\lambda) \rho W_{j}\left(\hat{\tau}_{s i}^{c}\left(\tau_{i-1}^{c}\right), \hat{\tau}_{s i}^{c}\left(\tau_{i-1}^{c}\right)\right)+\lambda \rho W_{i+1}\left(\hat{\tau}_{s i+1}^{c}\left(\tau_{i}^{c}\right), \hat{\tau}_{s i+1}^{c}\left(\tau_{j}^{c}\right)\right) \\
\left.+\lambda(1-\rho)\left[W_{i+1}\left(\tau_{i+1}^{c}, \tau_{i+1}^{c}\right)+K_{i+1}\right]\right\}-\frac{\delta}{1-\delta} W_{i}\left(\hat{\tau}^{N}, \hat{\tau}^{N}, \tau_{j-1}^{c}\right) \\
\equiv R_{i}\left(\tau_{j}^{c}, \tau_{j-1}^{c}, \tau_{i+1}^{c} ; K_{i+1}\right)
\end{gathered}
$$

Written in a form analogous to (28), (32) becomes 


$$
\begin{aligned}
& W_{i}\left(\tau_{i}^{c}, \tau_{i}^{c}\right)+\frac{\rho}{1-\rho} \frac{\lambda}{1-\lambda} W_{i+1}\left(\hat{\tau}_{s i+1}^{c}\left(\tau_{i}^{c}\right), \tau_{s i+1}^{c}\left(\tau_{i}^{c}\right)\right) \\
& \quad \geq\left[\frac{1-\delta(1-\lambda)(1-\rho)}{\delta(1-\lambda)(1-\rho)}\right]\left[W_{i}\left(\hat{\tau}^{N}, \tau_{i}^{c}, \tau_{i-1}^{c}\right)-W_{i}\left(\tau_{i}^{c}, \tau_{i}^{c}\right)\right. \\
& \left.+\frac{\delta}{1-\delta} W_{i}\left(\hat{\tau}^{N}, \hat{\tau}^{N}, \tau_{i-1}^{c}\right)\right]-\frac{\lambda}{1-\lambda}\left[W_{i+1}\left(\hat{\tau}^{N}, \hat{\tau}_{i+1}^{c}\left(\tau_{i}^{c}\right), \tau_{i}^{c}\right)\right. \\
& \left.+\frac{\delta}{1-\delta} W_{i+1}\left(\hat{\tau}^{N}, \hat{\tau}^{N}, \tau_{i}^{c}\right)\right]-\frac{\rho}{1-\rho} W_{i}\left(\tau_{s i}^{c}\left(\hat{\tau}_{i-1}^{c}\right), \tau_{s i}^{c}\left(\hat{\tau}_{i-1}^{c}\right)\right)
\end{aligned}
$$

As in the previous section, $\hat{\tau}_{n}^{c}\left(\tau_{n-1}^{c}\right)=0$ and $\hat{\tau}_{n-1}^{c}\left(\tau_{n-2}^{c}\right)$ can be characterized using (32). while $\hat{\tau}_{i}^{c}\left(\tau_{i-1}^{c}\right)$ for $i \in\{n-2, \ldots, 1\}$ can be derived recursively using (33), starting with $\mathrm{i}=\mathrm{n}-2$ under the knowledge that free trade is reached in the $n^{\text {th }}$ round. Figure 6 depicts $\hat{\tau}_{i}^{c}\left(\tau_{i-1}^{c}\right)$ in an analogous fashion to its depiction in Figure 5. But (31) determines $\hat{\tau}_{s}^{c}\left(\tau_{i-1}^{c}\right)$, and the question of whether existing tariff levels can be sustained when the liberalization process arrives at a premature end amounts to whether $\hat{\tau}_{s i}^{c}\left(\tau_{i-1}^{c}\right) \geq \frac{\hat{\tau}_{i}^{c}}{<}\left(\tau_{i-1}^{c}\right)$ for $i \in\{1, \ldots, n\}$, or, using (31) and (32), whether

$$
R_{1}\left(\hat{\tau}_{i}^{c}\left(\tau_{i-1}^{c}\right), \tau_{i-1}^{c}, \hat{\tau}_{i+1}^{c}\left(\hat{\tau}_{i}^{c}\right) ; \hat{K}_{i+1}\left(\hat{\tau}_{i}^{c}\right)\right) \frac{>}{<} X_{i}\left(\tau_{s i}^{c}=\tau_{i}^{c}\left(\tau_{i-1}^{c}\right), \tau_{i-1}^{c}\right)
$$

since at $\hat{\tau}_{i}^{c}, R_{i}()$ must decline in $\tau_{i}^{c}$ more slowly than the left-hand side of (32).

It is clcar that the maximum $\tau_{n-1}^{c}$ from which free trade can be reached in the $n^{\text {th }}$ round, $\overline{\tau_{n-1}^{c}}$, is equal to the maximum $\tau_{n-1}^{c}$ from which free trade could be sustained in the $n^{\text {th }}$ 
round in the event political will for future liberalizations were lost, denoted by $\overline{\tau_{n-1}^{c s}}$ in Figure

6. This reflects the fact that, with the nth round achieving free trade, the political will for future rounds of liberalization is irrelevant. However, under my assumption that any equilibrium retreat from liberal trade policies does not undo more liberalization than was achieved in the previous round, it is straightforward to prove by contradiction using (34) that $\hat{\tau}_{s i}^{c}\left(\tau_{i-1}^{c}\right)>\hat{\tau}_{i}^{c}\left(\tau_{i-1}^{c}\right)$ for $\tau_{i-1}^{c} \in\left[\overline{\tau_{n-1}^{c}, \tau_{0}^{c}}\right]$, since the discounted expected benefits of maintaining cooperation along the equilibrium path, given that future liberalization from $\hat{\tau}_{i}^{c}\left(\tau_{i-1}^{c}\right)$ is expected--the left-hand side of (34)--must be greater than the discounted benefits of maintaining stationary cooperation at $\hat{\tau}_{i}^{e}\left(\tau_{t-1}^{e}\right)-$-the right-hand side of (34). This is depicted in Figure 6. The right-hand panel depicts the most cooperative liberalization path for a hypothetical case taking three rounds to complete by the solid line, while the implications of a loss of political will after the second round are depicted by the dashed line. Hence, the political will for undertaking further liberalization is required to sustain current levels of liberalization. Put differently, a premature end to the liberalization process must lead to a retreat from the levels of tariff cutting achieved in previous rounds.

\section{v. Conclusion}

I have presented a model of trade liberalization in which "gradualism" is an cndogenous outcome. In order to do this, I have adopted many simplifying assumptions along the way. Some of these assumptions are inessential for the results, but others are 
clearly more substantive. In this section, I close by commenting on two of the more substantive.

First. I have focused on the resource movements in and out of import-competing sectors during the process of liberalization, but have ignored the analogous resource novements with regard to export sectors. If resources moving into the export sector must attain sector specific skills from which they then earn rents, the process I have modeled in the import sector could run in reverse in the export sector, eventually putting a halt to liberalization when the rent-earning resources in the export sector grow sufficiently large relative to the shrinking rent-earning resources in the import-competing sector. This possibility might be attenuated somewhat if one thinks of investments in the skills of the expanding industry as less industry-specific than those tailored to what is now a declining industry. But it is still an important consideration that 1 have ignored.

Second, I have maintained the assumption throughout that the resources moving out of the import-competing sector over time are atomistic. This is important, since knowing that today's departure of workers from the import-competing sector will set the stage for tomorrow's liberalization would generally give those workers who remain in the sector today an incentive to prevent the departure of their co-workers. In the formal model developed here, there are no workers earning inframarginal rents along the equilibrium liberalization path, but more generally such rents would be earned, and those earning them would have an incentive to "organize" to reduce the rate at which workers leave the import-competing sector. and thus the rate of future tariff liberalization. Consideration of non-atomistic import- 
competing resources would surely complicate the model, but would provide an interesting and important extension. 


\section{References}

Bagwell, Kyle, and Robert W. Staiger, "A Theory of Managed Trade," American Economic Review 80, September 1990, pp. 779-795.

Bagwell, Kyle, and Robert W. Staiger, "Multilateral Tariff Cooperation During the Formation of Free Trade Areas," NBER Working Paper No. 4364. 1993a.

Bagwell, Kyle, and Robert W. Staiger, "Multilateral Tariff Cooperation During the Formation of Customs Unions," NBER Working Paper No. 4543, 1993 b.

Bhagwati, Jagdish, Protectionism, The MIT Press, Cambridge, Mass., 1988.

Devereux, Michael B., "Growth, Specialization, and Trade Liberalization." mimeo, August 1992.

Dewatripont, M., and G. Roland, "Economic Reform and Dynamic Political Constraints," Review of Economic Studies 59, 1992, pp. 703-730.

Dixit, Avinash, "Strategic Aspects of Trade Policy," in Truman F. Bewley, ed.. Advances in Economic Theory: Fifth World Congress, New York: Cambridge University Press, 1987, 329-62.

Economic Report of the President, Transmitted to the Congress, February 1992.

Jensen. Richard, and Marie Thursby, "Free Trade: Two Noncooperative Approaches." Ohio State University Working Paper, 1984.

Matsuyama, Kiminori, "Perfect Equilibria in a Trade Liberalization Game," American Economic Review 80, June 1990, pp. 480-492. 
Figure 1

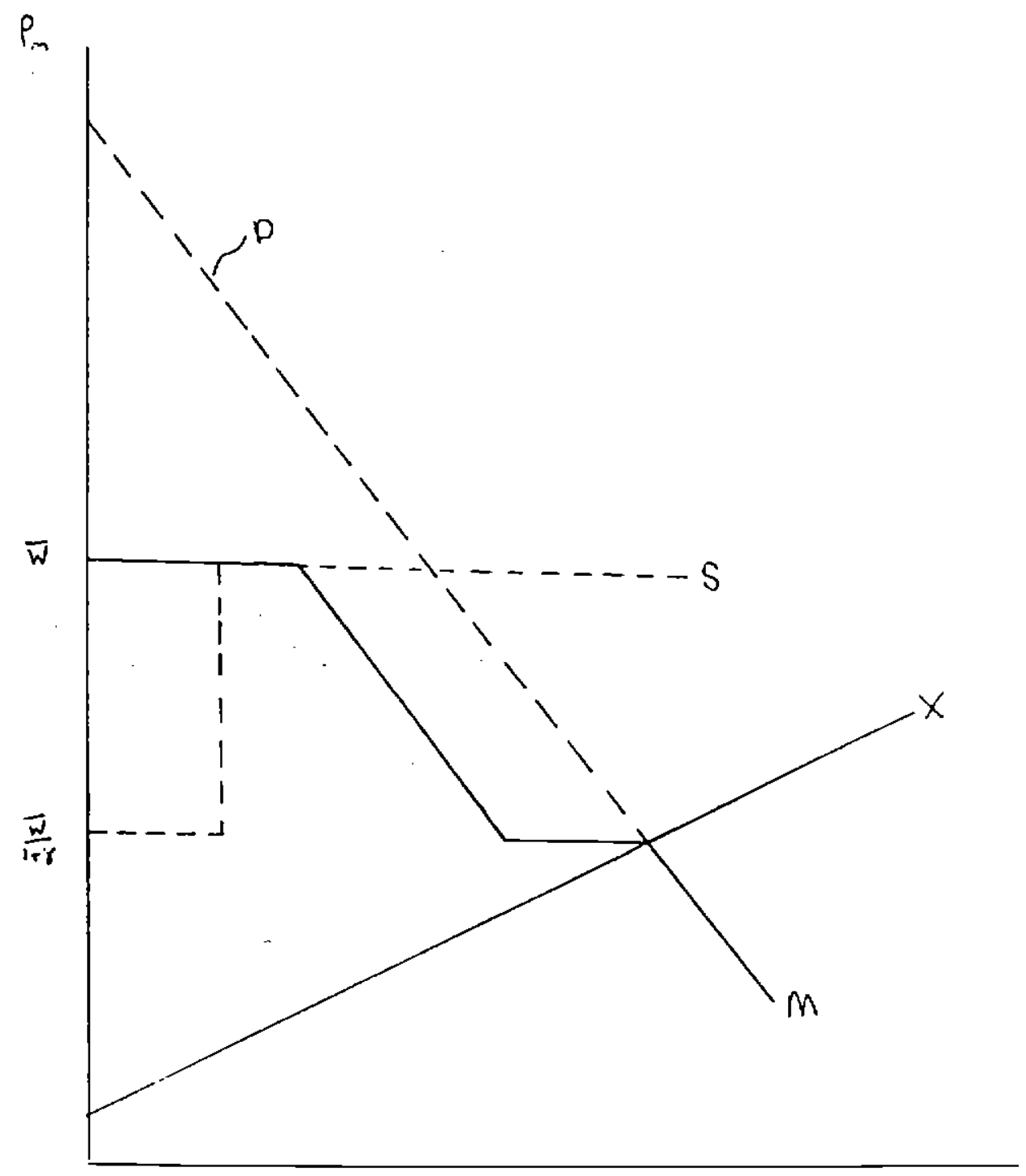


Figure 2

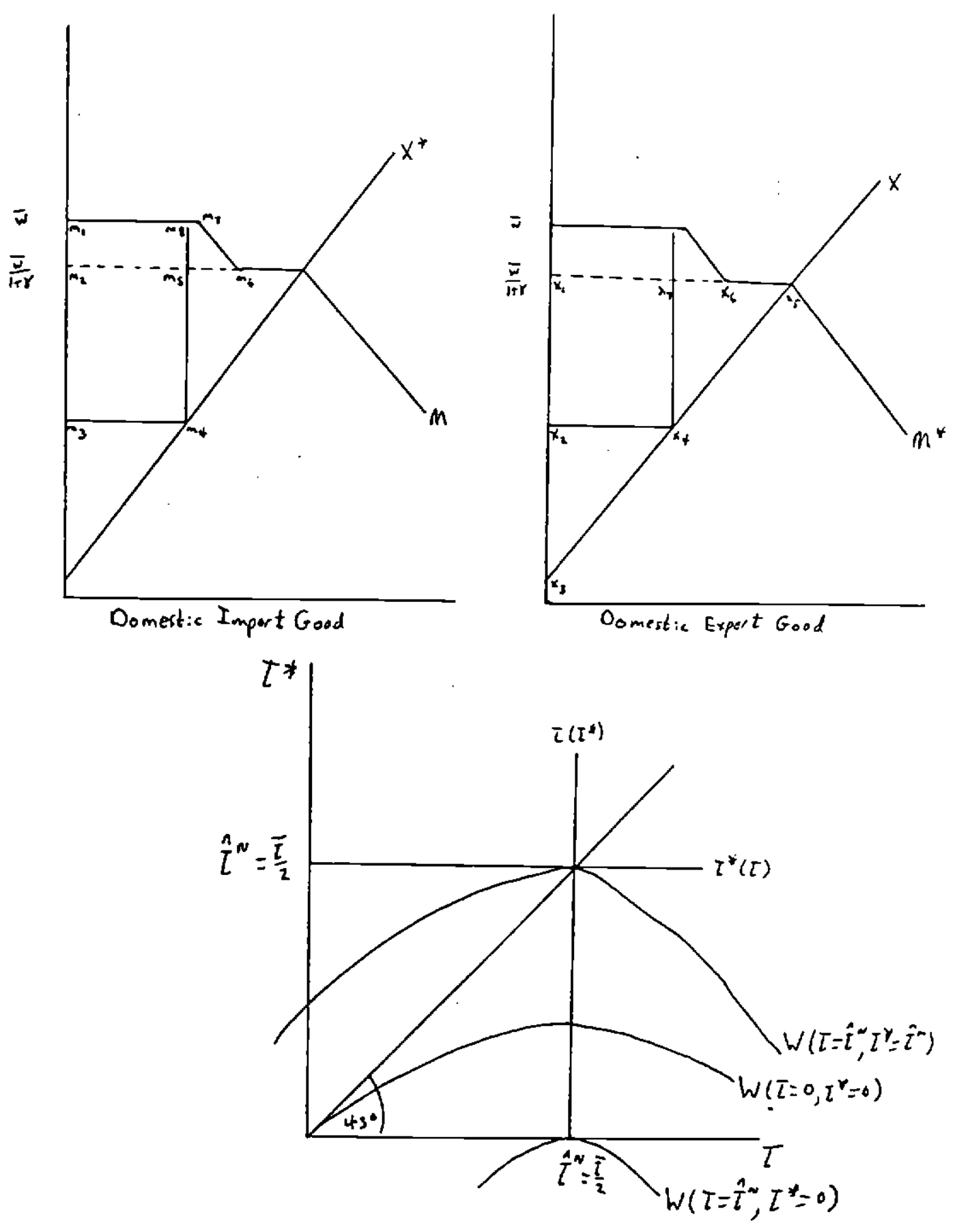


Fiqure 3

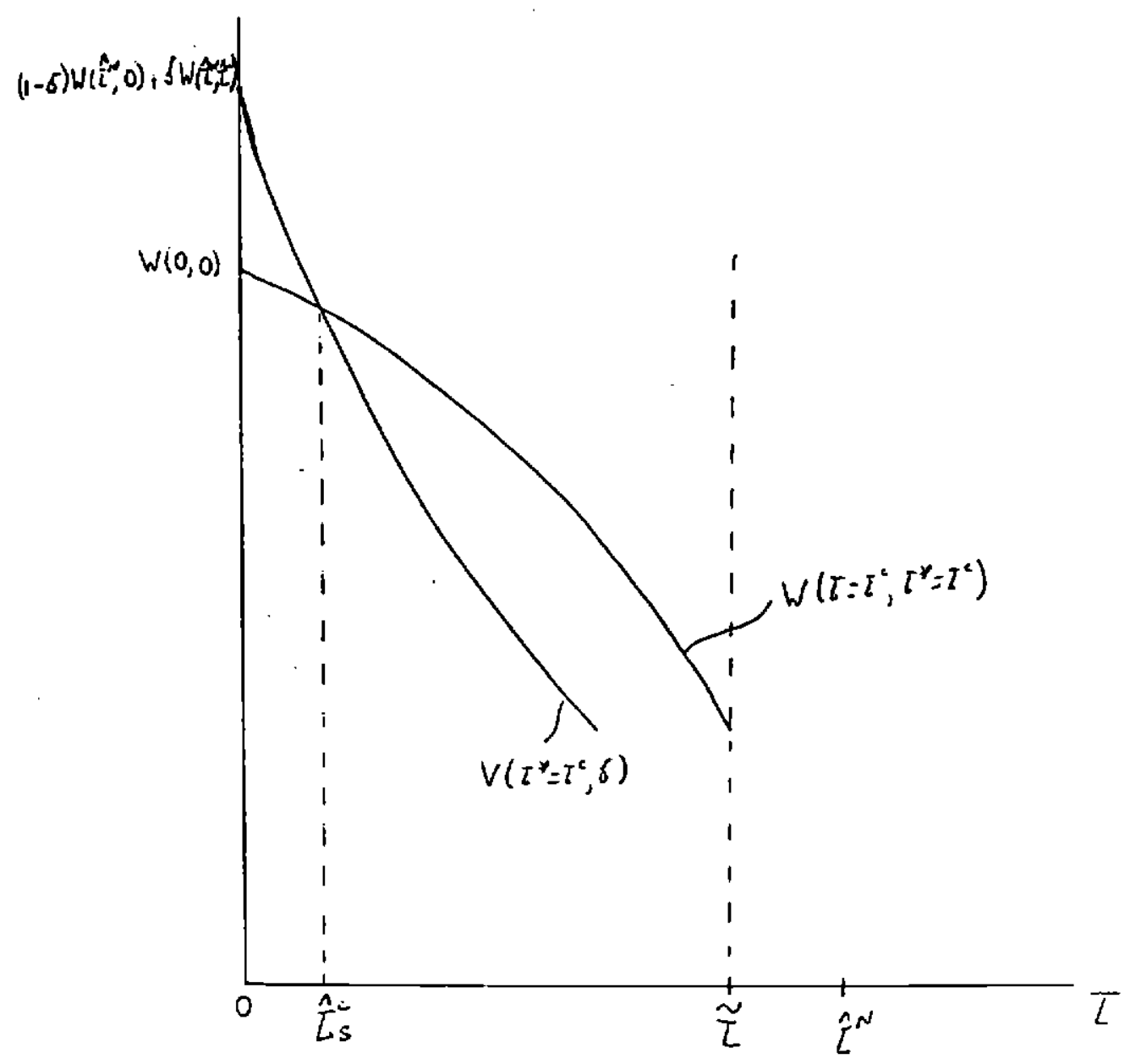


Figure 4




Figure S

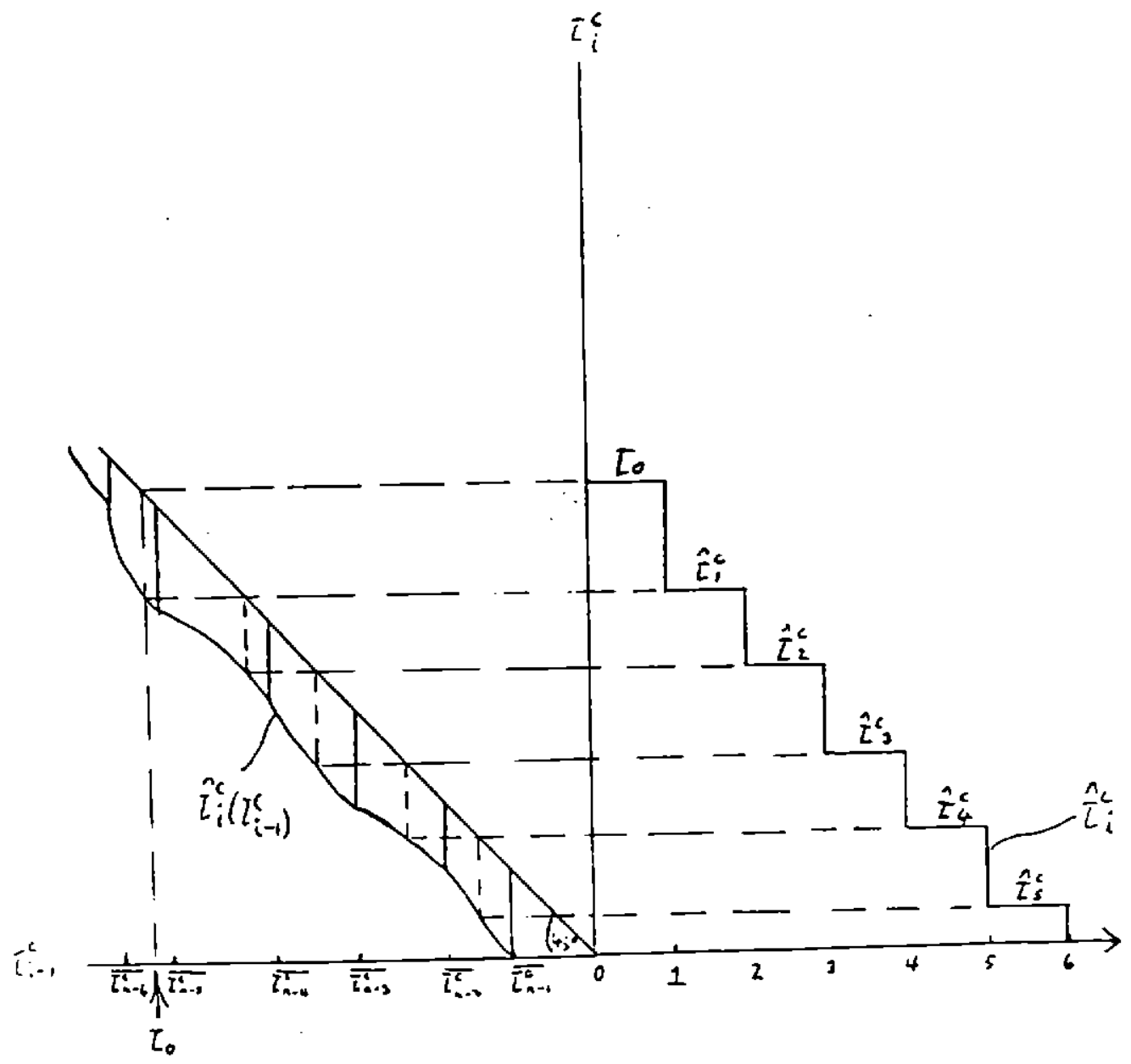




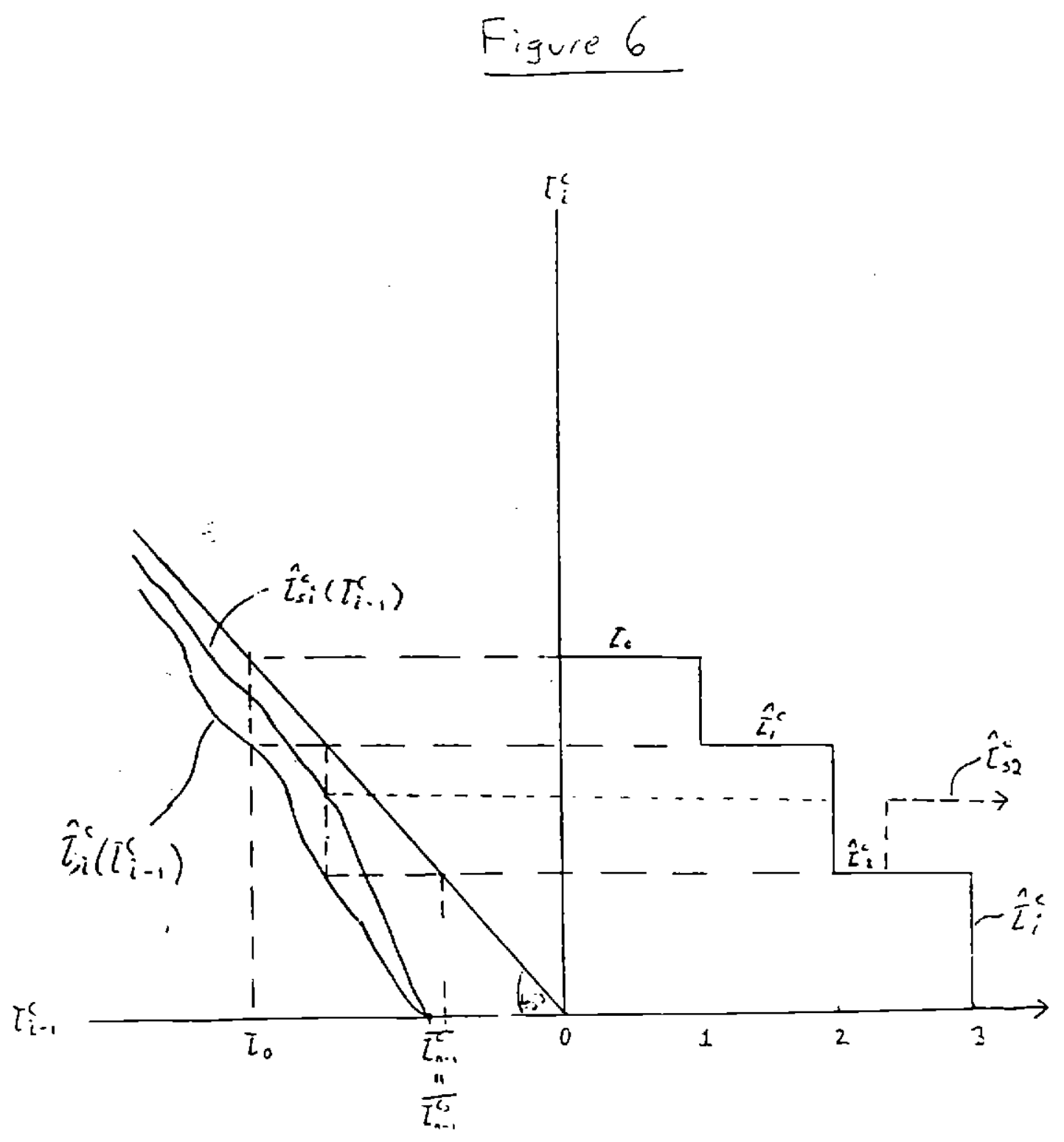

